\title{
Aluminium-phthalocyanine chloride nanoemulsions for anticancer photodynamic therapy: Development and in vitro activity against monolayers and spheroids of human mammary adenocarcinoma MCF-7 cells
}

\author{
Luis Alexandre Muehlmann ${ }^{1+}$, Mosar Corrêa Rodrigues ${ }^{2+}$, João Paulo Figueiró Longo ${ }^{2}$, Mônica Pereira Garcia², \\ Karen Rapp Py-Daniel ${ }^{2}$, Aline Bessa Veloso ${ }^{3}$, Paulo Eduardo Narciso de Souza ${ }^{3}$, Sebastião William da Silva ${ }^{3}$ \\ and Ricardo Bentes Azevedo ${ }^{2 *}$
}

\begin{abstract}
Background: Photodynamic therapy (PDT) combines light, molecular oxygen and a photosensitizer to induce oxidative stress in target cells. Certain hydrophobic photosensitizers, such as aluminium-phthalocyanine chloride (AIPC), have significant potential for antitumor PDT applications. However, hydrophobic molecules often require drug-delivery systems, such as nanostructures, to improve their pharmacokinetic properties and to prevent aggregation, which has a quenching effect on the photoemission properties in aqueous media. As a result, this work aims to develop and test the efficacy of an AIPC in the form of a nanoemulsion to enable its use in anticancer PDT.

Results: The nanoemulsion was developed using castor oil and Cremophor ELP®, and a monodisperse population of nanodroplets with a hydrodynamic diameter of approximately $25 \mathrm{~nm}$ was obtained. While free AIPc failed to show significant activity against human breast adenocarcinoma MCF-7 cells in an in vitro PDT assay, the AIPC in the nanoemulsion showed intense photodynamic activity. Photoactivated AIPc exhibited a $50 \%$ cytotoxicity concentration (CC50) of $6.0 \mathrm{nM}$ when applied to MCF-7 cell monolayers and exerted a powerful cytotoxic effect on MCF-7 cell spheroids.
\end{abstract}

Conclusion: Through the use of spontaneous emulsification, a stable AIPc nanoemulsion was developed that exhibits strong in vitro photodynamic activity on cancer cells.

Keywords: Spontaneous emulsification, Cancer, Drug delivery systems, Third-generation photosensitizers, Human breast adenocarcinoma MCF-7 cells, Spheroids

\section{Background}

Photodynamic therapy (PDT), as a cancer-treatment method, has a series of advantages over approaches such as surgery, chemotherapy and radiotherapy, as discussed elsewhere [1-5]. PDT is based on the production of oxidative species by a photosensitizer (PS), which is a

\footnotetext{
* Correspondence: razevedo@unb.br

${ }^{\dagger}$ Equal contributors

${ }^{2}$ Department of Genetics and Morphology, Institute of Biological Sciences, University of Brasilia, Federal District, Brazil

Full list of author information is available at the end of the article
}

molecule capable of converting specific light energy into chemical potential. In aerobic cells, the photoactivation of PS by a specific, targeted light source converts triplet oxygen $\left({ }^{3} \mathrm{O}_{2}\right)$ into the strongly oxidative species singlet oxygen $\left({ }^{1} \mathrm{O}_{2}\right)$, thereby triggering oxidative stress [2]. The oxidative stress has the potential to induce cell death or a therapeutically significant stress response. Thus, PDT anticancer mechanisms can include direct induction of cancer-cell death [6-8], vascular blockage with subsequent tumour ischemia [9], and increased immune response to tumour antigens $[1,2,10]$. 
Since the early 1980s, substantial efforts to advance PDT have focused on developing new and improved PS molecules and drug delivery systems $[4,6]$. The first generation of PS molecules consisted of complex mixtures of porphyrinoids that were extracted from blood and chemically modified $[4,11]$. These molecules exhibited promising anticancer PDT results, but prolonged retention by the skin and other issues hindered clinical application [4]. The second generation of PS molecules showed improved photodynamic activity and chemical purity, and skin accumulation was significantly lower compared to first-generation PS $[4,11]$. However, these molecules exhibited low selectivity for tumour cells and were exceedingly hydrophobic [12]. Drug delivery systems, such as polymeric nanoparticles and liposomes, have also been progressing over recent years and currently have the potential to improve upon the secondgeneration PS and thereby usher in a third generation of PS with new protocols and improved anticancer PDT results $[8,13,14]$.

Among second-generation PS, hydrophobic phthalocyanine derivatives are particularly good candidates for being associated to nanostructured drug delivery systems. Hydrophobic phthalocyanines are among the most efficient PS molecules and show excellent accumulation in cancerous cells $[12,15]$. On the other hand, hydrophobicity leads to rapid clearance from the body by mononuclear phagocytes and the hydrophobic molecules lose substantial photodynamic activity in aqueous media $[12,16]$. Previous works have described nanostructured systems that avoid some hydrophobicity-related drawbacks in aqueous media $[6,7,9,14]$. Unfortunately, most of these systems employ a high level of organic solvents and are not easily scaled up $[6,17,18]$. This work describes a new nanostructured system containing the hydrophobic PS aluminium-phthalocianine chloride (AlPc), which presents strong anticancer photodynamic activity, and is produced through a simple nanoemulsification method.

\section{Results and discussion}

\section{Effect of SOR on the nanoemulsion colloidal characteristics}

Hydrophobic phthalocyanine derivatives present intense and prolonged accumulation in cancerous cells [12]; however, at the same time, their hydrophobicity is a major drawback. This property confers a low circulation time in the bloodstream because hydrophobic phthalocyanine derivatives are more readily cleared by mononuclear phagocytes [12, 19]. Moreover, hydrophobic photosensitizers aggregate in aqueous systems, such as the cytosol and bloodstream, leading to an intense loss in photodynamic activity due to the quenching effect [20,21].

In the present work, a nanoemulsion produced by spontaneous nanoemulsification is proposed to improve the photodynamic activity of AlPc. Nanoemulsions are kinetically stable mixtures of immiscible liquids, consisting of a continuous phase containing dispersed nanodroplets (the dispersed phase, generally 20 to $300 \mathrm{~nm}$ in diameter) $[22,23]$, which can be easily produced on a large scale without the need for complex equipment or processes. The method used in this work, spontaneous nanoemulsification, is based on the generation of nanodroplets by the turbulent movement of surfactants from the oil to the oil-water interface after addition of an aqueous phase to the surfactant-oil mixture [22].

Cremophor ELP ${ }^{\circ}$ was used as the surfactant, while castor oil composed the oily phase. All of the nanoemulsions were of the oil-in-water type, as observed in conductivity experiments (data not shown). The average hydrodynamic diameter (HD) of nanodroplets was directly proportional to the surfactant-to-oil ratio (SOR, Fig. 1). This phenomenon has been previously reported [22] and is due to the larger mean volume of oil per droplet. Nanoemulsions with narrow size distributions (polydispersity index - PDI - of approximately 0.1 ) were obtained with an SOR between 0.5 and 0.9. Anton and Vandamme [22] described nanoemulsions obtained by spontaneous emulsification with Cremophor ELP ${ }^{\bullet}$ as the surfactant and Labrafil M1944 $\mathrm{CS}^{\circ}$ as the oil with a SOR of 0.2. The higher SOR needed for producing castor oil nanoemulsions observed in the present work is probably due to the different chemical composition of castor oil as it is a mixture of triacylglycerols containing hydroxy fatty acids, mainly ricinoleic acid, while Labrafil M1944 $\mathrm{CS}^{\circ}$ is more easily emulsified because it contains polyoxyl moieties and is thus less hydrophobic than castor oil. In subsequent experiments, the SOR was kept at 0.75 . This formulation was chosen because of its monodispersion and low average HD of the nanodroplets, which can facilitate the diffusion of nanodroplets in biological tissues $[24,25]$.

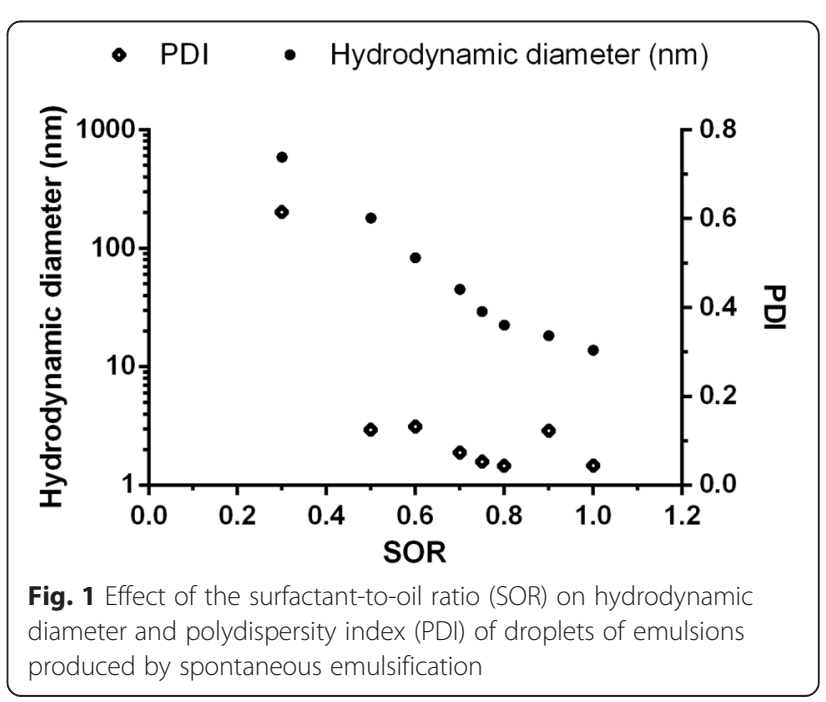


Effect of the AIPc concentration in the surfactant/oil mixture (SOmix) on the photo-triggered production of reactive species and the colloidal and photophysical properties of nanoemulsions

As the concentration of PS profoundly affects its photodynamic activity $[6,26,27]$, nanoemulsions produced with different initial AlPc concentrations were tested for their colloidal, photophysical and photochemical properties.

The concentration of AlPc in the surfactant/oil mixture (SOmix) did not affect the HD and PDI nor did it affect the light absorption of nanoemulsions prepared with a SOR of 0.75 (Fig. 2). However, there was a significant influence of the concentration of AlPc in the SOmix on the fluorescence of nanoemulsions $\left(\mathrm{R}_{\text {Pearson }}=1.0\right.$ for concentrations ranging from 46 to $444 \mu$ mol.kg $\left.{ }^{-1}, \mathrm{p}<0,05\right)$. All of the nanoemulsions, except S0, were diluted to $1.0 \mu \mathrm{M}$ AlPc prior to fluorescence measurements to ensure that the aggregation state of AlPc was the only factor affecting fluorescence and light absorption.

The system with the highest concentration of AlPc in SOmix tested, S722 $\left(722 \mu\right.$ mol. $\left.\mathrm{kg}^{-1}\right)$, presented a low fluorescence intensity and low ability to produce reactive oxygen species (ROS) under irradiation. This fact may be explained by the quenching effect. At certain high

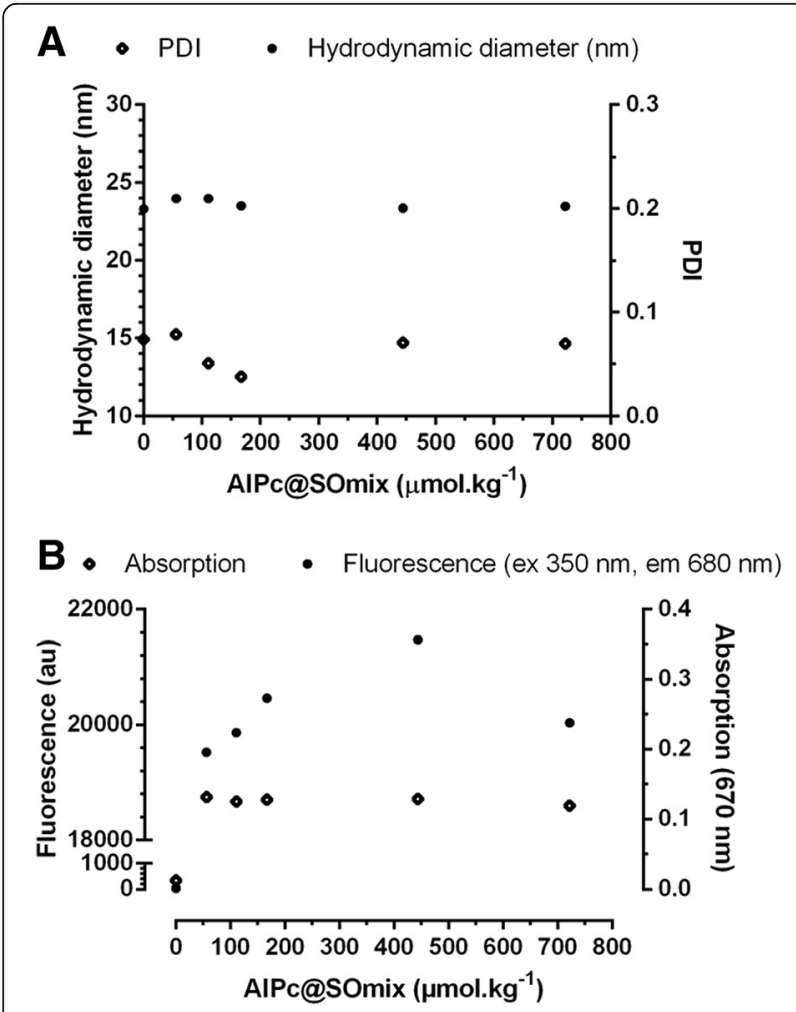

Fig. 2 Effects of the AIPc concentration in the surfactant/oil mixture (AIPc@SOmix) on the (a) hydrodynamic diameter and polydispersity index (PDI) of nanodroplets and on (b) fluorescence (excitation $350 \mathrm{~nm}$, emission $680 \mathrm{~nm}$ ) and light absorption ( $670 \mathrm{~nm}$ ) of nanoemulsions produced by spontaneous emulsification concentrations of AlPc, similar to the case for other fluorescent molecules, the distance between molecules is short enough to facilitate the quenching effect $[6,26,27]$. The nanoemulsion produced with AlPc $444 \mu \mathrm{mol} \cdot \mathrm{kg}^{-1}$ in SOmix (S444) presented light absorption and fluorescence intensity comparable to that of AlPc in ethanol, which is a good solvent for this molecule. This formulation was then chosen for subsequent experiments.

As expected, the results of photo-triggered production of ROS by nanoemulsions (Fig. 3) match the fluorescence intensity results. The most intense production of ROS was observed for the S167 and S444 nanoemulsions, with their maximum production reached at an energy density of $2.95 \mathrm{~J} / \mathrm{cm}^{2}$. The lowest rate of ROS generation was obtained with $\mathrm{S} 722$, with a maximum production reached only at $5.18 \mathrm{~J} / \mathrm{cm}^{2}$. As expected, S0 did not produce ROS under irradiation.

The colloidal properties of S444 and S0 in different dispersants are presented in Table 1 . The zeta potential of these formulations was close to zero, reflecting the neutral nature of the nanodroplets, which was expected due to the interfacial stabilization performed by the

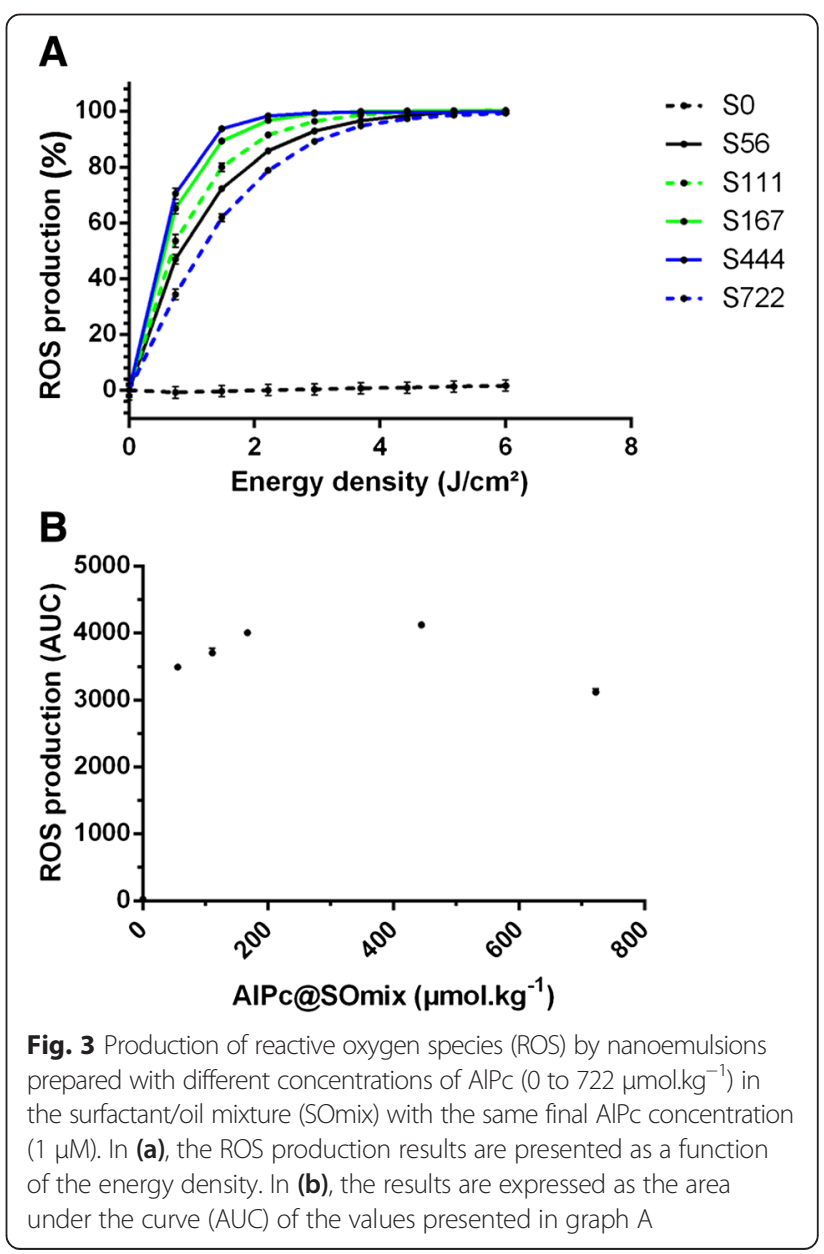


Table 1 Colloidal properties of S444 and S0 nanoemulsions in different dispersants

\begin{tabular}{llll}
\hline $\begin{array}{l}\text { Nanoemulsion/ } \\
\text { Dispersant }\end{array}$ & $\begin{array}{l}\text { Hydrodynamic } \\
\text { diameter }(\mathrm{nm})\end{array}$ & PDI & Zeta potential $(\mathrm{mV})$ \\
\hline S444/PBS & $25.08 \pm 0.28$ & $0.131 \pm 0.02$ & $-6.24 \pm 0.47$ \\
S444/DMEN & $25.57 \pm 2.34$ & $0.130 \pm 0.09$ & $-3.15 \pm 1.54$ \\
S444/DMEN F12 & $25.89 \pm 1.23$ & $0.109 \pm 0.03$ & $-2.95 \pm 0.96$ \\
S0/PBS & $24.33 \pm 0.27$ & $0.094 \pm 0.03$ & $-3.84 \pm 0.56$ \\
\hline
\end{tabular}

neutral, hydrophilic polyoxyl moieties of Cremophor ELP $^{\circledR}$ and not by surface charge.

The absorption and fluorescence spectra of S444 and S0 are presented in Fig. 4. As expected, free AlPc neither significantly absorbed light nor emitted fluorescence when dispersed in water. However, when dissolved in ethanol, AlPc absorbs light with a peak at $670 \mathrm{~nm}$ and emits fluorescence at $674 \mathrm{~nm}$ when excited with light at $350 \mathrm{~nm}$. AlPc in the S444 nanoemulsion absorbed light with a peak at $674 \mathrm{~nm}$ and emitted fluorescence at $684 \mathrm{~nm}$ when excited with light at $350 \mathrm{~nm}$. Both the absorption and fluorescence intensity of AlPc in S444 were close to those observed in ethanol. As expected, S0 neither presented significant absorption nor fluorescence superposing the peaks presented by AlPc. The peak observed at $710 \mathrm{~nm}$ in the fluorescence spectra is an artefact of the equipment.

\section{Colloidal and photophysical stability of an AIPC nanoemulsion (S444)}

The HD of S444 did not change over the evaluation time at the storage temperatures tested (data not shown). Moreover, PDI remained near 0.1 along the period of analysis, reflecting the stability and monodispersion of the nanodroplet size. The AlPc content did not vary significantly during the time of analysis. Additionally, both the absorption of light at $676 \mathrm{~nm}$ and fluorescence intensity (excitation $350 \mathrm{~nm}$, emission $680 \mathrm{~nm}$ ) did not significantly vary over the time of evaluation.

\section{SERS and Raman spectra}

In order to verify the aggregation state of AlPc, SERS and Raman spectra of AlPc under different conditions were produced. Fig. 5 presents the SERS spectra of nanoemulsions S56, S167, S444 and S722 (Fig. 5b-e), all of which at $1 \mu \mathrm{M}$ AlPc. For comparison, the normal
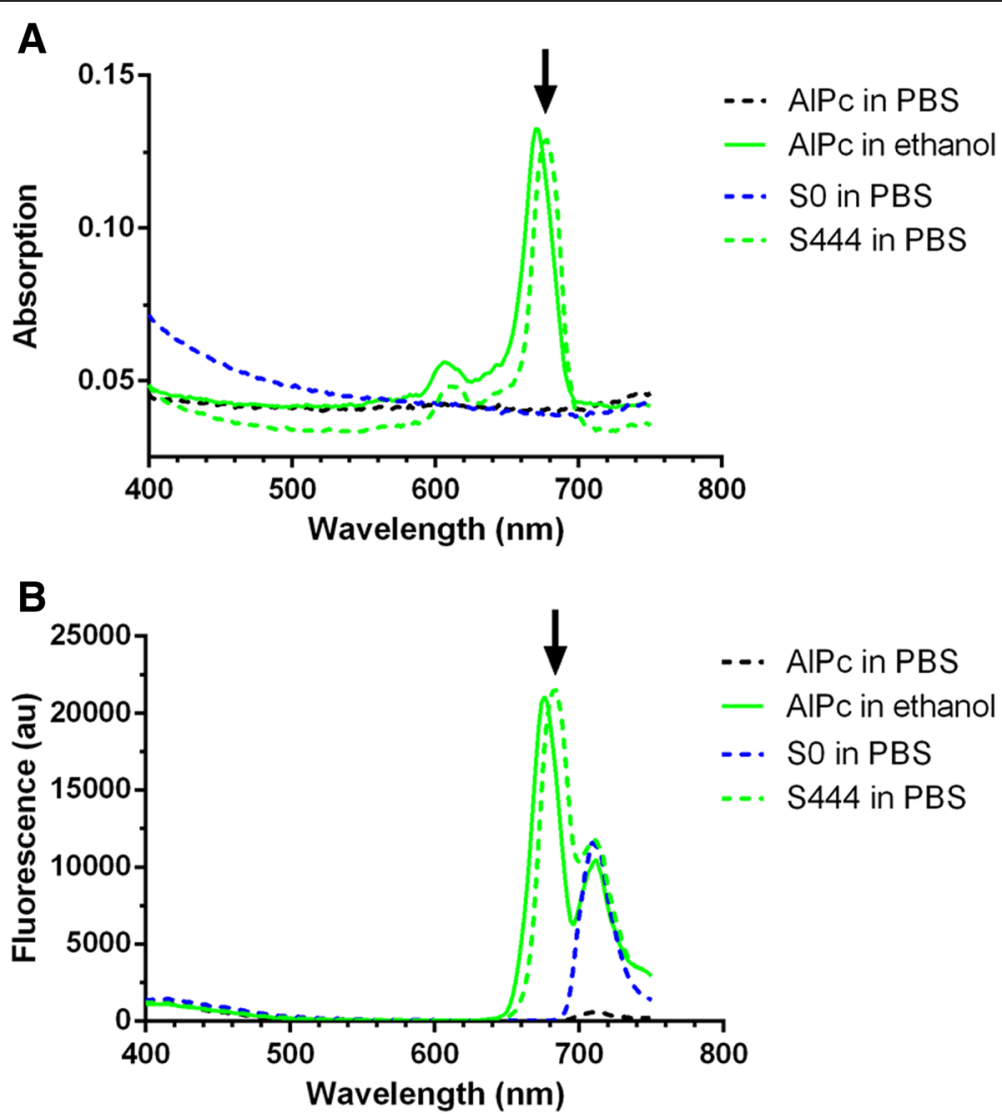

Fig. 4 Absorption (a) and fluorescence (b, excitation at $350 \mathrm{~nm}$ ) spectra of $1 \mu \mathrm{M}$ free AIPC in PBS or ethanol and of a blank nanoemulsion (S0) and S444 (1 $\mu \mathrm{M}$ AIPC) dispersed in PBS. The peaks at $710 \mathrm{~nm}$ in $\mathbf{b}$ are artefacts of the equipment 


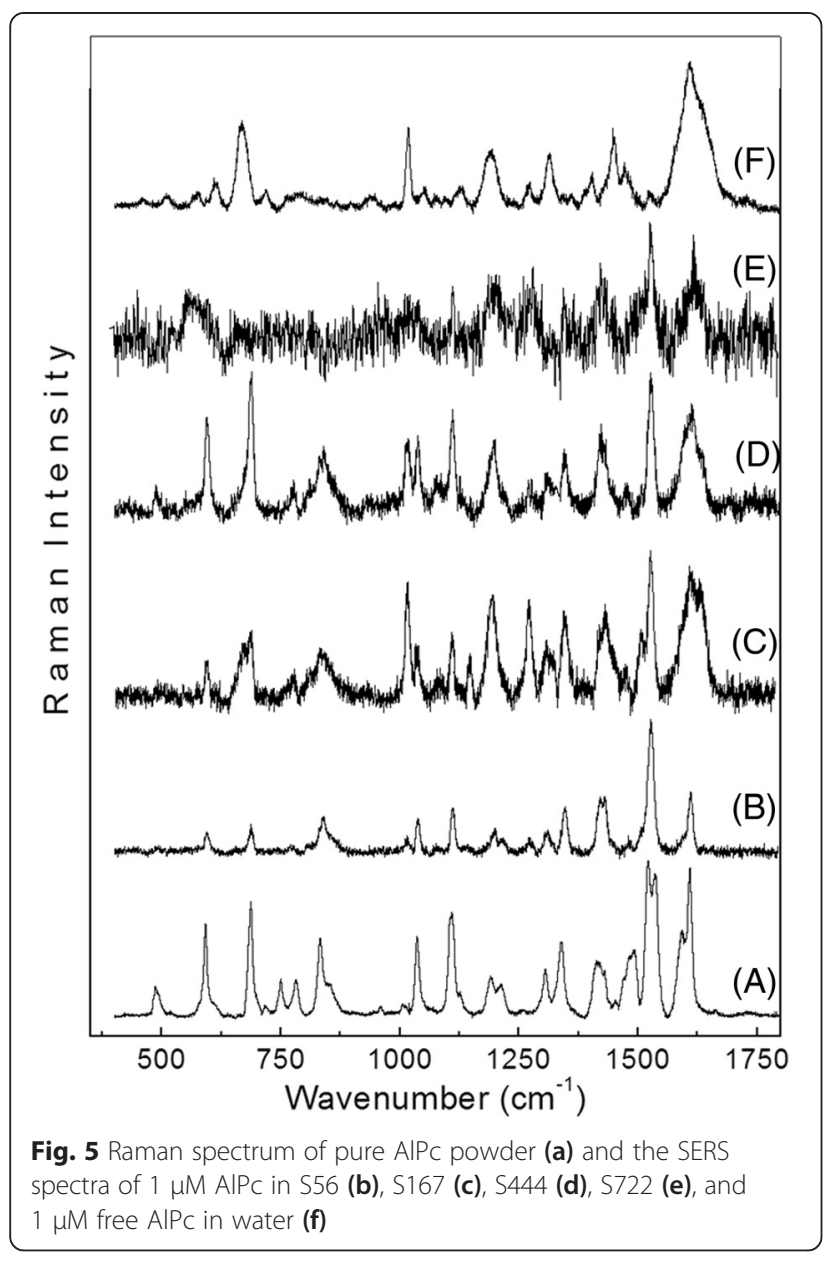

Raman spectrum for the AlPc powder (Fig. 5a) and the SERS spectrum of a $1 \mu \mathrm{M}$ dispersion of free AlPc in water (Fig. 5f) are also shown.

Figure 5a presents a typical Raman spectrum of AlPc powder. Despite the fact that the AlPc molecule displays highly coupled vibrational modes, it is possible to affirm that the Raman spectrum is dominated by vibrations from benzene (at approximately 690, 1110, 1190, 1310, 1340, 1410,1590 and $1615 \mathrm{~cm}^{-1}$ ), macrocycle (at approximately 590, 750, 830 and 1520 and $1538 \mathrm{~cm}^{-1}$ ) and pyrrole (at approximately 830, 1040 and $1210 \mathrm{~cm}^{-1}$ ) [28]. On the other hand, the SERS spectrum of free AlPc in water is significantly different from the Raman spectrum of AlPc powder. The most remarkable differences are the near complete absence of the vibrational modes from the central region of the AlPc (macrocycle and pyrrole) and the shift in the vibrational modes from the benzene ring.

The surface-enhanced Raman spectroscopy (SERS) spectra of the nanoemulsion samples exhibit similar characteristics to the Raman spectrum of AlPc powder. However, a careful analysis shows important differences. The spectrum for the AlPc powder differs from the spectra of the nanoemulsion samples in relation to the presence or absence of certain bands and in the relative intensities of some peaks. For example, the peak at $750 \mathrm{~cm}^{-1}$, assigned to the vibrations of the $C_{\alpha}-N_{\alpha}-C_{\alpha}$ and $\mathrm{Al}-\mathrm{N}_{\alpha}$ bonds, is present in the spectrum of the AlPc powder, but the peak is absent in the nanoemulsion spectra. In addition, the decrease in the relative intensities between the vibrations related to the central regions of the AlPc molecules $\left(I_{c}\right)$ (peaks at 830, 1040 and $1520 \mathrm{~cm}^{-1}$ ) and the vibrations related to the benzene group located at the edges of the AlPc molecule $\left(I_{e d}\right)$ (peaks at 1190, 1410 and $1615 \mathrm{~cm}^{-1}$ ).

These findings suggest an aggregation tendency with increasing concentrations of AlPc in SOmix. This result, particularly, is aligned to the photophysical (fluorescence and light absorption intensities) and photochemical (phototriggered ROS production) observations presented before. It is clear that $I_{c} / I_{e d}$ decreases with increasing concentrations of AlPc, tending towards the SERS spectrum of AlPc in water, in which the vibrational modes of the central region of the AlPc molecule are absent. For example, the ratio $I_{c} / I_{e d}$, between the peaks at 1520 and $1410 \mathrm{~cm}^{-1}$ is 2.2, 2.0, 1.5, 1.2 and 0.7 for the AlPc powder and the nanoemulsions S56, S176, S444 and S722, respectively. Similar behaviours are observed for the ratios between the peaks at 1036 and $1190 \mathrm{~cm}^{-1}$, 1520 and $1615 \mathrm{~cm}^{-1}$, and 830 and $1190 \mathrm{~cm}^{-1}$.

Aggregation occurs due to AlPc-AlPc interactions involving the large planar aromatic ring systems, and the resulting formation of ordered structures with the AlPc benzene rings was preferentially located on the surface of aggregates [29]. Because the SERS enhancement factor decays with $1 / r^{12}$, the SERS spectra of aggregates depend on the dominant chemical species closer to $\mathrm{Ag}$ nanoparticles used in this method, which are preferentially the benzene rings located on the edge of the AlPc molecule in this case. This finding explains the absence of the modes from the central region of the AlPc molecule and the prevalence of vibrational modes of benzene rings in the SERS spectra.

\section{S444-mediated PDT in monolayers of MCF-7 and MCF-10A cells in vitro}

As nanoemulsion S444 showed better photodynamic activity due to low AlPc aggregation, this formulation was used for the in vitro tests with cells. At all the concentrations tested, S444 did not significantly affect the viability of cancerous (MCF-7) and non-cancerous (MCF-10A) cells in the dark. Absence of toxicity in the dark is a general requirement for PS systems $[4,30,31]$ because it assures that only the tissues containing the PS and that are irradiated will be affected by the toxic effects of PDT. LED light alone did not significantly affect the viability of tested cells (data not shown). Moreover, S0 (blank nanoemulsion) 
was not cytotoxic to MCF-7 or MCF-10A cells in the dark or after irradiation at concentrations equivalent to those tested for S444 (see Additional file 1: Figure S1 in supplementary information).

MCF-7 and MCF-10A cells showed different susceptibilities to S444 after irradiation with LED light $(660 \mathrm{~nm}$, $4.4 \mathrm{~J} / \mathrm{cm}^{2}$ ). As shown in Fig. 6, there was a significant decrease in MCF-7 cell viability in all of the S444 AlPc concentrations tested $(\mathrm{p}<0.001)$, with $50 \%$ cytotoxic concentration $\left(\mathrm{CC}_{50}\right)$ and $100 \%$ cytotoxic concentration $\left(\mathrm{CC}_{100}\right)$ of 3.0 and $93.0 \mathrm{nM}$, respectively. For MCF-10A, PDT reduced cell viability, although these cells were less affected in comparison to MCF-7 cells, with photoactivated S444 presenting a $\mathrm{CC}_{50}$ and $\mathrm{CC}_{100}$ of 6.0 and $625.0 \mathrm{nM}$, respectively. Thus, the values of $\mathrm{CC}_{50}$ and $\mathrm{CC}_{100}$ of $\mathrm{S} 444$ in MCF-10A for photoactivated S444 were 2- and 6.7-fold higher, respectively, compared to those observed in MCF-7 cells.

The more intense effect against MCF-7 cells may be due to the higher endocytic activity that is frequently observed in cancerous cells [32]. A similar result was observed in a previous work involving AlPc in polymeric nanoparticles, which were more active against MCF-7 cells in comparison to MCF-10A cells [6]. That work also showed that MCF-7 cells were more sensitive to PDT mediated by AlPc in nanoparticles.

\section{S444-mediated PDT against spheroids of MCF-7 cells in vitro}

Figure 7c shows the evolution of MCF-7 cells in culture from a monolayer to a spheroid of approximately $200 \mu \mathrm{m}$ in diameter. In comparison to cell monolayers, in vitro cell

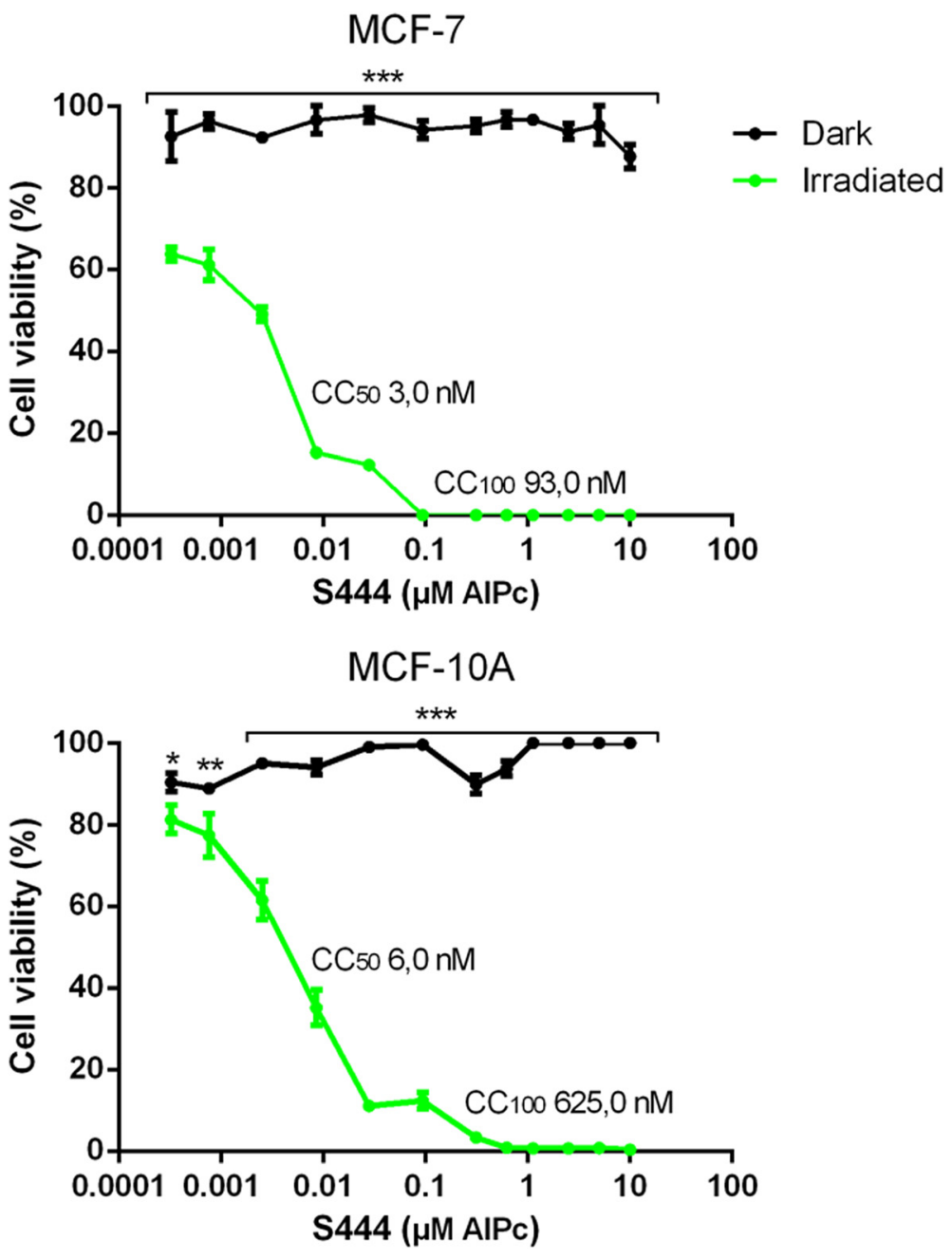

Fig. 6 Viability of cancerous (MCF-7, human) and non-cancerous (MCF-10A, human) cells exposed to different concentrations of S444 for 15 min and then kept in the dark or irradiated $\left(660 \mathrm{~nm}, 4.4 \mathrm{~J} / \mathrm{cm}^{2}\right)$. Cell viability was evaluated by the MTT method $24 \mathrm{~h}$ after treatment. The $\mathrm{CC}_{50}$ and $\mathrm{CC}_{100}$ of $\mathrm{S} 444$ after irradiation were 3.0 and $93.0 \mathrm{nM}$, respectively. ${ }^{*} \mathrm{p}<0.05$, ${ }^{* *} \mathrm{p}<0.01$, and ${ }^{* * *} \mathrm{p}<0.001$, for dark vs irradiated 


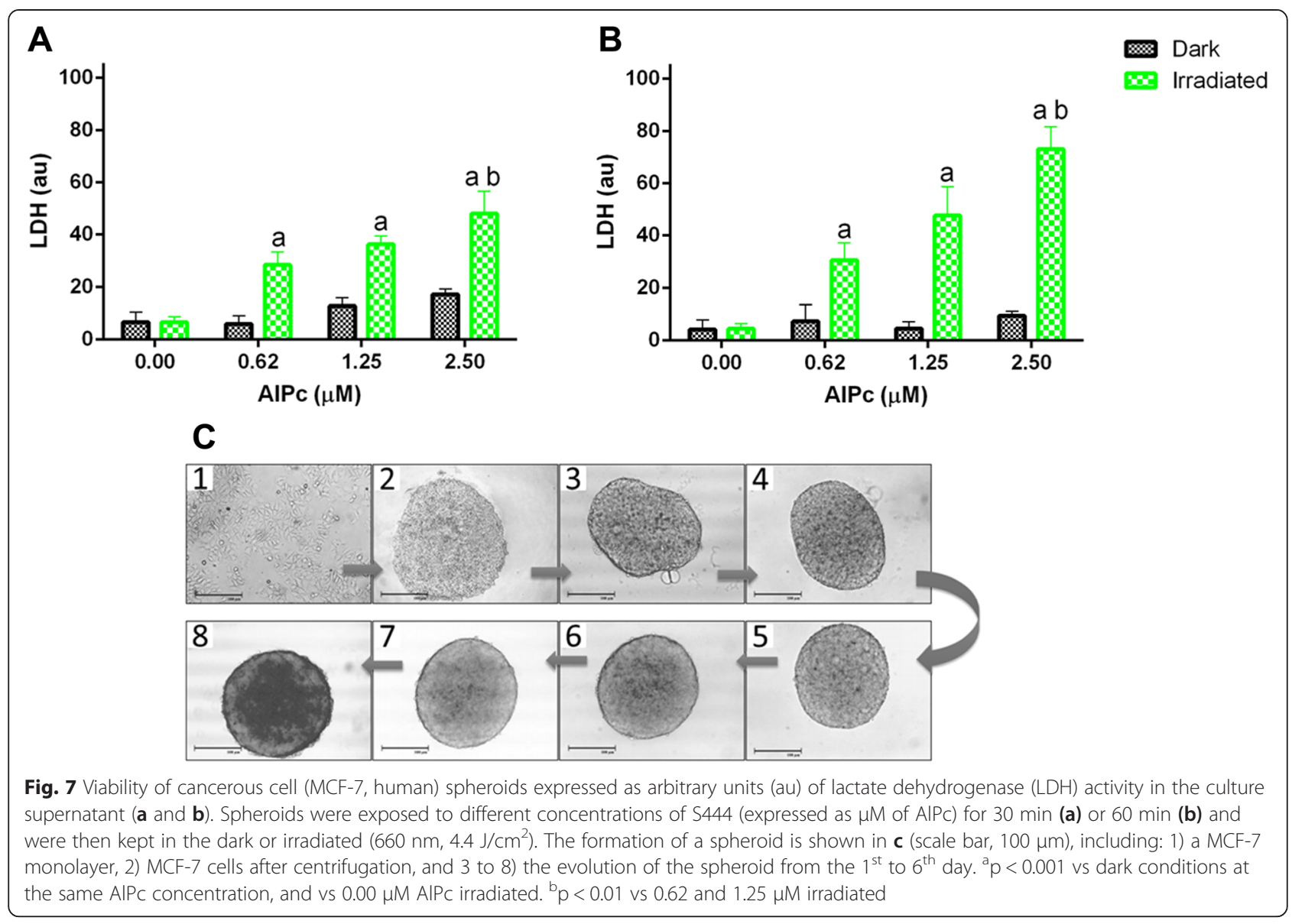

spheroids more accurately mimic the architecture of tumours, which show tumour cells on the surface while hiding other cells on spheroids [33, 34]. MCF-7 cell spheroids were sensitive to S444-mediated PDT in vitro. As expected, significant toxicity to MCF-7 cells was observed only when S444 and light irradiation were combined. This effect was dependent on the concentration of AlPc. Irradiation or S444 alone did not significantly induce spheroid cells lysis.

The concentration- and exposure time-dependent pattern of toxicity induction is probably associated with the extension of AlPc permeation in spheroids. When spheroids were exposed for $30 \mathrm{~min}$ to $\mathrm{S} 444$ at 1.25 and $2.50 \mu \mathrm{M}$ AlPc, PDT increased the release of LDH by only 2.8 -fold. However, when the exposure time was increased to $60 \mathrm{~min}$, PDT based on S444 at 1.25 and $2.50 \mu \mathrm{M}$ AlPc induced, respectively, 10.5- and 7.8-fold increases in $\mathrm{LDH}$ release. Thus, S444-mediated PDT induced an intense lysis of cancer cell spheroids to an even greater extent than that reported in previous works with conventional chemotherapeutic drugs [34]. This result shows that S444 has a great potential for permeating cancer cell spheroids, since its efficacy is directly dependent on permeation through spheroids. Therefore, future in vivo anticancer tests with S444 must take into account the permeation time of S444 in tumour tissues to optimize the PDT protocol.

\section{Cellular distribution of S444 in MCF-7 cells}

MCF-7 cells exposed for 15 min to S444 presented AlPc in the cytoplasm but not in nuclei, as shown in Fig. 8. The oxidative species generated by a photoactivated photosensitizer diffuse for only a few nanometers [2], being thus restricted to the site where the photosensitizer is concentrated. Thus, the AlPc distribution pattern observed in this study may prevent PDT-mediated DNA damage and resistance-inducing modifications in the cell genome [1].

\section{Conclusion}

This work reported the development of a nanoemulsion containing AlPc, a hydrophobic phthalocyanine derivative. This formulation showed intense photodynamic activity in aqueous media and thus was effective in reducing the viability of adenocarcinoma MCF-7 cells in vitro, both as monolayers and spheroids. It remains to be tested in in vivo tumour models, however, whether 


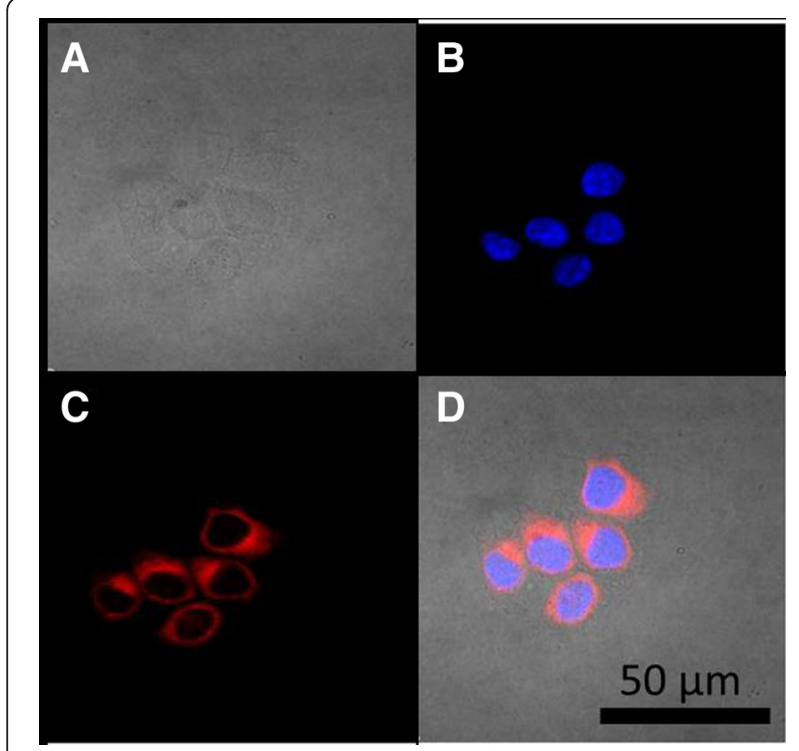

Fig. 8 Internalization of S444 (125 nM AIPC) by MCF-7 cells in vitro after 15 min of exposure. AIPc appears in red, while nuclei are stained blue by 4',6-diamidino-2-phenylindole (DAPI). a) bright field. b) cell nuclei in blue. c) AIPC in red. $\mathbf{d}$ ) merge of $\mathbf{a}, \mathbf{b}$ and $\mathbf{c}$

further selectivity for tumours may be achieved with the use of this nanoemulsion.

\section{Materials and methods}

The reagents employed in this work are as follows: Dulbecco's modified Eagle's medium (DMEM, HyClone, Logan, USA); DMEM:F12 (HyClone, Logan, USA); Penicillin, streptomycin and foetal bovine serum (Gibco, Grand Island, NY, USA); Anti-fading agent (ProLong Gold, Life sciences); Phosphate-buffered saline (Laborclin, Pinhais, Paraná, Brazil); Dimethyl sulfoxide and ethanol (Vetec, Xerém, Rio de Janeiro, Brazil); HPLC-grade methanol and ethanol (Mallinckrodt Inc., Hazelwood, MO, USA); ACSgrade trifluoroacetic acid (TFA) (Vetec, Duque de Caxias, RJ, Brazil); Milli-Q water (Barnstead EASYpure II Thermo Scientific, San Jose, CA, USA); Cell lines: human mammary adenocarcinoma MCF-7 cells (Rio de Janeiro Cell Bank [RJCB], Rio de Janeiro, Brazil), human mammary epithelial MCF-10A cells (kindly provided by Dr. Maria Mitzi Brentani, University of São Paulo, São Paulo, Brazil). All other materials were purchased from Sigma (São Paulo, Brazil).

\section{Production of nanoemulsions with different surfactant-to-oil ratios}

Cremophor ELP ${ }^{\ominus}$ (polyoxyl-35 castor oil) was used as a surfactant [22]. Different mixtures of Cremophor ELP ${ }^{\circledR}$ and castor oil (SOmix) were produced for final surfactantto-oil weight ratios (SOR, SOR = surfactant weight/ surfactant weight + oil weight) ranging from 0.3 to 1.0 . Then, $70 \mathrm{~mL}$ of distilled water were added to $12 \mathrm{~g}$ of each
SOmix at RT with mild magnetic stirring (300 RPM for $15 \mathrm{~min})$. Next, the volume was adjusted to $100 \mathrm{~mL}$ with distilled water, and the systems were kept at RT for $24 \mathrm{~h}$. The hydrodynamic diameter (HD, Z-average size), zeta potential, and PDI of droplets dispersed in each system were then measured according to the protocol in the section titled "Colloidal properties".

\section{Production of nanoemulsions with different concentrations of AIPc in SOmix}

Nanoemulsions were prepared with a fixed amount of SOmix $\left(75 \%\right.$ Cremophor ELP ${ }^{\oplus}$ and $25 \%$ castor oil, w:w, $\mathrm{SOR}=0.75)$ containing different concentrations of AlPc. In this experiment, AlPc was first dissolved in ethanol $99{ }^{\circ} \mathrm{GL}$ at a concentration of $1.7 \mathrm{mM}$. Then, different volumes of the AlPc solution were added to $12 \mathrm{~g}$ of SOmix aliquots so that the AlPc concentrations ranged from 56 to $722 \mu \mathrm{mol} . \mathrm{kg}^{-1}$. Ethanol was then removed at $100{ }^{\circ} \mathrm{C}$ under mild magnetic stirring (300 RPM for $15 \mathrm{~min})$. Next, solutions of AlPc in SOmix were left to cool to RT, and $70 \mathrm{~mL}$ of distilled water were added under mild stirring. These systems were further stirred for $15 \mathrm{~min}$ at RT, and the volumes were adjusted to $100 \mathrm{~mL}$ with distilled water. A nanoemulsion without AlPc was prepared through this same procedure $(\mathrm{S} 0)$. Throughout this work, nanoemulsions are named by their respective AlPc concentrations in the SOmix preceded by the letter S, e.g., "S56" represents the system prepared with SOmix containing AlPc at $56 \mu$ mol. $\mathrm{kg}^{-1}$. This nomenclature was adopted to distinguish the concentration of AlPc in the SOmix from the concentration of AlPc in the final nanoemulsion. Nanoemulsion properties were analysed according to the sections titled "Colloidal properties", "Photophysical properties" and "Detection of reactive oxygen species".

\section{Colloidal properties}

The hydrodynamic diameter (HD) and zeta potential of droplets dispersed in water were measured at $25{ }^{\circ} \mathrm{C}$ by photon correlation spectroscopy and electrophoretic laser Doppler velocimetry (ZetaSizer Nano ZS ${ }^{\bullet}$, Malvern Instruments, Malvern, UK), respectively. The polydispersity index (PDI) was calculated using the equipment software for DLS measurements. All measurements were performed in triplicate and the results are presented as the mean \pm SEM.

\section{Photophysical properties}

The fluorescence intensity and light absorption were measured with a spectrophotometer (Spectramax ${ }^{\circ}$ M2, Molecular Devices, Sunnyvale, CA, USA) at $25{ }^{\circ} \mathrm{C}$ in 96-well microplates. In all experiments, nanoemulsions were diluted to $1 \mu \mathrm{M}$ AlPc before fluorescence or absorption measurements were performed. 


\section{Surface-enhanced raman spectroscopy (SERS)}

Silver colloid was prepared by reducing $\mathrm{AgNO}_{3}$ with an excess of trisodium citrate, $\mathrm{Na}_{3} \mathrm{C}_{6} \mathrm{H}_{5} \mathrm{O}_{7}$ [35]. Then, $25 \mu \mathrm{L}$ of each nanoemulsion sample was diluted in aliquots of $25 \mu \mathrm{L}$ of silver colloid, and Raman spectra were immediately recorded. The Raman (for pure AlPc powder) and SERS spectra (for all other samples) were obtained in the backscattering configuration and analysed using a triple spectrometer (Jobin Yvon Model T64000; Horiba, Tokyo Japan) equipped with a CCD detector. Samples were illuminated at $488 \mathrm{~nm}$ with an Argon ion laser at an optical power of $20 \mathrm{~mW}$.

\section{AIPc quantification by HPLC}

The chromatographic equipment (Shimadzu-Prominence) consisted of an on-line degasser (Model DGU 20A5), solvent delivery module (Model LC-20AT), autosampler (Model SIL-20AHT), column oven (Model CTO-20A), fluorescence detector (Model RF-10AXL) and system controller CBM-20A. A reverse-phase C8 column Vydac of $5 \mu \mathrm{m}, 4.6 \mathrm{~mm} \times 250 \mathrm{~mm}$ (Thermo Fischer Scientific, Massachusetts, USA) with a pre-column of $5 \mu \mathrm{m}, 4.6 \mathrm{~mm} \times$ $50 \mathrm{~mm}$ (Thermo Fischer Scientific, Massachusetts, USA) was used. The mobile phase consisted of a mixture of $0.12 \%$ (m:v) TFA in Milli-Q water (pump A) and methanol (pump B) at 40:60 (v/v) rendering an isocratic phase. Fluorimetric measurements were carried out in a $12-\mu \mathrm{L}$ flow cell at 610 and $675 \mathrm{~nm}$ excitation and emission wavelengths, respectively. The injection volume was $5 \mu \mathrm{l}$ and the flow rate was $1 \mathrm{ml} / \mathrm{min}$ at a working pressure of 135 kgf.cm ${ }^{-2}$. Analyses were performed with a column temperature of $30{ }^{\circ} \mathrm{C}$. LCsolution Software (Shimadzu, Tokyo, Japan) was used for data processing.

The calibration curve was generated with AlPc solutions with concentrations ranging from 0.01 to $8 \mu \mathrm{M}$. For AlPc quantification in nanoemulsions, sample aliquots were dissolved in ethanol $(1: 40, \mathrm{v} / \mathrm{v})$, vortexed for $3 \mathrm{~min}$, filtered through $0.22-\mu \mathrm{m}$ nylon filters (Millex GN, Millipore, Darmstadt, Germany), and injected into the HPLC system.

\section{Nanoemulsion stability}

The colloidal and photophysical stability of S444 was evaluated for 365 days. Briefly, 200- $\mu \mathrm{L}$ aliquots of S444 were kept in the dark at $4{ }^{\circ} \mathrm{C}, 25^{\circ} \mathrm{C}$ or $37^{\circ} \mathrm{C}$. At specific times of storage, one aliquot of each nanoemulsion was tested for nanodroplet hydrodynamic diameter, PDI (see section "Colloidal properties"), light absorption $(676 \mathrm{~nm})$, fluorescence intensity (excitation at $350 \mathrm{~nm}$, emission at $680 \mathrm{~nm}$ ) (see section "Photophysical properties"), and AlPc content (see section "AlPc quantification by HPLC").

\section{Detection of reactive oxygen species}

Reactive oxygen species (ROS) were detected by an indirect method, employing the probe 1,3-diphenylisobenzofuran
(DPBF), as described elsewhere [36, 37]. In a typical experiment, $10 \mu \mathrm{L}$ of DPBF in ethanol $(225 \mu \mathrm{g} / \mathrm{mL})$ was added to $200 \mu \mathrm{L}$ of sample in a transparent 96-well microplate. Then, absorption at $410 \mathrm{~nm}$ was recorded at $25{ }^{\circ} \mathrm{C}$ with a spectrophotometer before and immediately after irradiation of the sample with light energy densities ranging from 0.1 to $6.0 \mathrm{~J} / \mathrm{cm}^{2}$. The absorption values were normalized, and the optical density at $410 \mathrm{~nm}$ before irradiation was considered to be $0 \%$, while the lower plateau absorption values were considered to be $100 \%$ ROS generation. The results were expressed as ROS production (\%) as a function of energy density or area under the curve (AUC). This experiment was performed in triplicate.

\section{Cell culture}

MCF-7 cells were cultured in DMEM, supplemented with $10 \%$ (v:v) foetal bovine serum and a $1 \%$ (v:v) antibiotic solution $(100 \mathrm{IU} / \mathrm{mL}$ penicillin and $100 \mathrm{mg} / \mathrm{mL}$ streptomycin). MCF-10A cells were cultured in DMEM:F12 $(1 / 1, \mathrm{v}: \mathrm{v})$ supplemented with $5 \%$ (v:v) equine serum, $20 \mathrm{ng} / \mathrm{mL}$ epidermal growth factor (EGF), $10 \mu \mathrm{g} / \mathrm{mL}$ bovine insulin, $0.5 \mu \mathrm{g} / \mathrm{mL}$ hydrocortisone, $100 \mathrm{ng} / \mathrm{mL}$ cholera toxin, and $1 \%$ (v:v) antibiotic solution (100 IU/mL penicillin and $100 \mathrm{mg} / \mathrm{mL}$ streptomycin). All cells were maintained at $37^{\circ} \mathrm{C}$ in a $5 \% \mathrm{CO}_{2}$ humidified atmosphere.

\section{Intracellular distribution of S444}

The intracellular localization of the AlPc nanoemulsion S444 was visualized by confocal microscopy. Briefly, MCF-7 cells were cultured on coverslips placed in 24-well plates for $24 \mathrm{~h}$ according to the conditions described in the "Cell culture" section at a density of $2 \times 10^{4}$ cells/well. Next, the cells were exposed to S444 diluted in culture medium at a concentration equivalent to $125 \mathrm{nM}$ AlPc for $15 \mathrm{~min}$ at $37{ }^{\circ} \mathrm{C}, 5 \% \mathrm{CO}_{2}$ and humidified atmosphere. Then, the cells were washed twice with PBS, fixed with $4 \%$ (w:v) paraformaldehyde for $15 \mathrm{~min}$, stained with DAPI, washed twice with PBS, and mounted on glass slides with anti-fading agent. Next, the cells were visualized by a confocal microscope (Leica, TCS SP5, São Paulo, Brazil). AlPc fluorescence was detected with excitation at $405 \mathrm{~nm}$ and emission at $633 \mathrm{~nm}$. DAPI fluorescence was detected with an excitation at $358 \mathrm{~nm}$ and emission at $461 \mathrm{~nm}$.

\section{Formation of MCF-7 cell spheroids}

Spheroids were obtained based on a protocol described elsewhere [34]. Briefly, $50 \mu \mathrm{L}$ of $1.5 \%$ low melting agarose ( $w: v$ in distilled water) were added to the wells of a 96-well microplate. Next, $1.5 \times 10^{4}$ MCF-7 cells, which were processed as described in the "Cell culture" section, were seeded on each well, and the microplate was then centrifuged for $15 \mathrm{~min}$ at $1500 \times \mathrm{g}$. Microplates were maintained at $37{ }^{\circ} \mathrm{C}$ in a $5 \% \mathrm{CO}_{2}$ humidified atmosphere. 
Formation of spheroids was monitored daily and photographed with an inverted microscope (Olympus Co., Tokyo, Japan) equipped with a digital camera (Moticam 2300 3.0MP, Life Resolution, Brazil). Microplates were maintained under these culture conditions until spheroids of approximately $200 \mu \mathrm{m}$ in diameter were obtained (generally, for approximately 6 days). Each well contained one single spheroid. Then, specific treatments were applied according to the "Cell treatment design" section.

\section{Cell treatment design}

MCF-7 and MCF-10A cells in monolayers were maintained as described in the "Cell culture" section and the cells were 1) exposed only to culture medium without additional treatment; 2) irradiated with LED light (660 nm) at an energy density of $4.4 \mathrm{~J} / \mathrm{cm}^{2} ; 3$ ) exposed to nanoemulsions without AlPc (S0) dispersed in culture medium for $15 \mathrm{~min}$ in the dark at castor oil concentrations of $0.19,0.38$ and $0.76 \%$ (w:v), equivalent to 2.5, 5.0 and $10.0 \mu \mathrm{M}$ AlPc, if compared to S444; 4) exposed to S444 diluted in culture medium for $15 \mathrm{~min}$ in the dark at concentrations ranging from $0.3 \mathrm{nM}$ to $10.0 \mu \mathrm{M}$ AlPc; or 5) exposed to S444 diluted in culture medium for $15 \mathrm{~min}$ in the dark at concentrations ranging from $0.3 \mathrm{nM}$ to $10.0 \mu \mathrm{M}$ AlPc, washed twice with PBS, and then irradiated with LED light $(660 \mathrm{~nm})$ at an energy density of $4.4 \mathrm{~J} / \mathrm{cm}^{2}$. Next, the cells were cultured for $24 \mathrm{~h}$ under the conditions described in the "Cell culture" section, and viability was assessed by the MTT assay, as described in the "MTT method for cell viability assessment" section.

MCF-7 cell spheroids were maintained as described in the "Formation of MCF-7 cell spheroids" section. Next, spheroids were exposed for 30 or $60 \mathrm{~min}$ to culture medium only (no AlPc control) or to S444 at concentrations equivalent to $0.62,1.25$, or $2.50 \mu \mathrm{M}$ AlPc. For each of these treatments, one-half of the wells containing spheroids was kept in the dark while the other half was irradiated with LED light $(660 \mathrm{~nm})$ at an energy density of $4.4 \mathrm{~J} / \mathrm{cm}^{2}$. After the treatments, cell lysis was quantified by the amount of lactate dehydrogenase released in the culture supernatant as described in the "Lactate dehydrogenase method for cell lysis assessment" section.

\section{MTT method for cell viability assessment}

Cell viability was assessed by the classical method of mitochondrial reduction of 3,4,5-dimethylthiazol-2,5 biphenyl tetrazolium bromide (MTT) by viable cells to an insoluble purple formazan [38]. Briefly, after receiving the respective treatment (see "Cell treatment design"), cells were washed twice with PBS and then incubated with $0.5 \mathrm{mg} / \mathrm{mL}$ MTT in culture medium for $2.5 \mathrm{~h}$ at $37{ }^{\circ} \mathrm{C}, 5 \% \mathrm{CO}_{2}$ and humidified atmosphere. Next, the MTT solution was removed, and formazan was extracted from cells with $200 \mu \mathrm{L}$ of DMSO. The formazan-specific light absorption was then measured at $595 \mathrm{~nm}$ with a spectrophotometer (Spectramax M2, Molecular Devices, USA). This experiment was performed three times, and the results are expressed as a percentage relative to the control.

\section{Lactate dehydrogenase method for cell lysis assessment}

The viability of spheroid cells was assessed by the quantification of lactate dehydrogenase activity by a colorimetric assay (CytoTox $9^{\circ}$, Promega Corp., Madison, WI, USA). Briefly, $40 \mu \mathrm{L}$ of the supernatant of spheroid cultures were mixed with $40 \mu \mathrm{L}$ of CytoTox $96^{\circ}$, and the mixture was kept in the dark for $30 \mathrm{~min}$. Next, light absorption was recorded at $490 \mathrm{~nm}$. The results were expressed as arbitrary units $(\mathrm{au})$ of lactate dehydrogenase activity.

\section{Statistical analyses}

All statistical analyses were performed with GraphPad Prism 5.0 software. Correlation between variables was analysed with the Pearson or Spearman test. Significant differences between groups were assessed by one-way analysis of variance (ANOVA) followed by Tukey or Bonferroni's post-tests $(\alpha=0.05)$. Results are expressed as mean \pm standard error of the mean.

\section{Additional file}

Additional file 1: Figure S1. Viability of non-cancerous (MCF-10A, human) and cancerous (MCF-7, human) cells exposed to different concentrations of SO (nanoemulsion without AIPC) for $15 \mathrm{~min}$, and then kept in the dark or irradiated $\left(660 \mathrm{~nm}, 4.4 \mathrm{~J} / \mathrm{cm}^{2}\right)$. Cell viability was evaluated by the MTT method $24 \mathrm{~h}$ after treatment.

\section{Competing interests}

The authors declare that they have no competing interests.

\section{Authors' contributions}

All the authors helped discussing the results. LAM conceived the study, developed and characterized the nanoemulsions, and drafted the

manuscript. MCR and JPFL performed in vitro tests with cells. KRP developed the method for HPLC dosage of aluminium-phthalocyanine and carried out the nanoemulsion stability experiments. PENS, ABV and SWS carried out SERS and Raman measurements. PENS developed the light source system used in PDT experiments. RBA conceived the study, participated in its design and drafted the manuscript. All authors read and approved the final manuscript.

\section{Acknowledgements}

Financial support from the Brazilian agencies MCT/CNPq, FINEP, CAPES, FAP/DF, and FINATEC is gratefully acknowledged.

\section{Author details}

${ }^{1}$ Faculty of Ceilandia, University of Brasilia, Federal District, Brazil.

${ }^{2}$ Department of Genetics and Morphology, Institute of Biological Sciences, University of Brasilia, Federal District, Brazil. ${ }^{3}$ Department of Physics, University of Brasilia, Federal District, Brazil.

Received: 26 February 2015 Accepted: 1 May 2015

Published online: 13 May 2015

\section{References}

1. Agostinis P, Berg K, Cengel KA, Foster TH, Girotti AW, Gollnick SO, et al. Photodynamic therapy of cancer: an update. CA Cancer J Clin. 2011;61(4):250-81. 
2. Dougherty TJ, Gomer CJ, Henderson BW, Jori G, Kessel D, Korbelik M, et al. Photodynamic therapy. J Natl Cancer Inst. 1998;90(12):889-905.

3. Velloso NV, Muehlmann LA, Longo JPF, Silva JR, Zancanela DC, Tedesco AC, et al. Aluminum-phthalocyanine chloride-based photodynamic therapy inhibits PI3K/Akt/mTOR pathway in oral squamous cell carcinoma cells in vitro. Chemotherapy. 2012;1 (107):5.

4. Yano S, Hirohara S, Obata M, Hagiya Y, Ogura S-i, Ikeda A, et al. Current states and future views in photodynamic therapy. Journal of Photochemistry and Photobiology C: Photochemistry Reviews. 2011;12(1):46-67.

5. Monge-Fuentes $V$, Muehlmann LA, Bentes de Azevedo R. Perspectives on the application of nanotechnology in photodynamic therapy for the treatment of melanoma. Nano Reviews. 2014;5.

6. Muehlmann LA, Ma BC, Longo JPF, Santos MFMA, Azevedo RB. Aluminumphthalocyanine chloride associated to poly (methyl vinyl ether-co-maleic anhydride) nanoparticles as a new third-generation photosensitizer for anticancer photodynamic therapy. Int J Nanomedicine. 2014;9:1199.

7. Longo JPF, MuehImann LA, Velloso NV, Simioni A, Lozzi S. Effects of photodynamic therapy mediated by liposomal aluminum-phthalocyanine chloride on chemically induced tongue tumors. Chemotherapy. 2012; (103):2.

8. Muehlmann LA, Joanitti GA, Silva J, Longo JPF, Azevedo RB. Liposomal photosensitizers: potential platforms for anticancer photodynamic therapy. Braz J Med Biol Res. 2011:44(8):729-37.

9. Mijan M, Longo J, Melo L, Simioni A, Tedesco A. Vascular shutdown and pro-inflammatory cytokine expression in breast cancer tumors after photodynamic therapy mediated by nano-sized liposomes containing aluminium-chloride-phthalocyanine. J Nanomed Nanotechnol. 2014;5(218):2.

10. Castano AP, Mroz P, Hamblin MR. Photodynamic therapy and anti-tumour immunity. Nat Rev Cancer. 2006;6(7):535-45

11. Ormond AB, Freeman HS. Dye sensitizers for photodynamic therapy. Materials. 2013;6(3):817-40.

12. Chan W-S, Marshall JF, Svensen R, Bedwell J, Hart IR. Effect of sulfonation on the cell and tissue distribution of the photosensitizer aluminum phthalocyanine. Cancer Res. 1990;50(15):4533-8.

13. Wainwright M. Photodynamic therapy: the development of new photosensitisers. Anti-Cancer Agents in Medicinal Chemistry (Formerly Current Medicinal Chemistry-Anti-Cancer Agents). 2008;8(3):280-91.

14. Lu H-L, Syu W-J, Nishiyama N, Kataoka K, Lai P-S. Dendrimer phthalocyanineencapsulated polymeric micelle-mediated photochemical internalization extends the efficacy of photodynamic therapy and overcomes drug-resistance in vivo. J Control Release. 2011;155(3):458-64.

15. O'Connor AE, Gallagher WM, Byrne AT. Porphyrin and nonporphyrin photosensitizers in oncology: preclinical and clinical advances in photodynamic therapy. Photochem Photobiol. 2009;85(5):1053-74.

16. Darwent JR, Douglas P, Harriman A, Porter G, Richoux M-C. Metal phthalocyanines and porphyrins as photosensitizers for reduction of water to hydrogen. Coord Chem Rev. 1982:44(1):83-126.

17. Primo FL, Rodrigues M, Simioni AR, Bentley MV, Morais PC, Tedesco AC. $<i>$ In vitro </i studies of cutaneous retention of magnetic nanoemulsion loaded with zinc phthalocyanine for synergic use in skin cancer treatment. J Magn Magn Mater. 2008;320(14):e211-4.

18. Rodrigues GB, Primo FL, Tedesco AC, Braga GU. In vitro photodynamic inactivation of Cryptococcus neoformans melanized cells with chloroaluminum phthalocyanine nanoemulsion. Photochem Photobiol. 2012:88(2):440-7.

19. Kobayashi M, Kigawa Y, Satoh K, Sawada K. Solvent effect on the aggregation of amphiphilic phthalocyanines substituted by polyethyleneoxide. J Porphyrins Phthalocyanines. 2012;16(02):183-91.

20. Li H, Jensen TJ, Fronczek FR, Vicente MGH. Syntheses and properties of a series of cationic water-soluble phthalocyanines. J Med Chem. 2008;51(3):502-11.

21. Darwent JR, Douglas P, Harriman A, Porter G, Richoux MC. Metal phthalocyanines and porphyrins as photosensitizers for reduction of water to hydrogen. Coord Chem Rev. 1982:44(1):837126.

22. Anton N, Vandamme TF. The universality of low-energy nano-emulsification. Int J Pharm. 2009;377(1):142-7.

23. Anton N, Vandamme TF. Nano-emulsions and micro-emulsions: clarifications of the critical differences. Pharm Res. 2011;28(5):978-85.

24. Albanese A, Tang PS, Chan WC. The effect of nanoparticle size, shape, and surface chemistry on biological systems. Annu Rev Biomed Eng. 2012;14:1-16
25. Perrault SD, Walkey $C$, Jennings T, Fischer HC, Chan WC. Mediating tumor targeting efficiency of nanoparticles through design. Nano Lett. 2009;9(5):1909-15.

26. Lovell JF, Liu TWB, Chen J, Zheng G. Activatable photosensitizers for imaging and therapy. Chemical Reviews. 2010;110(5):2839-57. doi:10.1021/cr900236h

27. Master AM, Rodriguez ME, Kenney ME, Oleinick NL, Gupta AS. Delivery of the photosensitizer Pc 4 in PEG-PCL micelles for in vitro PDT studies. Journal of Pharmaceutical Sciences. 2010;99(5):2386-98.

28. Basova TV, Kiselev VG, Plyashkevich VA, Cheblakov PB, Latteyer F, Peisert H, et al. Orientation and morphology of chloroaluminum phthalocyanine films grown by vapor deposition: Electrical field-induced molecular alignment. Chem Phys. 2011:380(1):40-7.

29. Udal'tsov AV, Bolshakova AV, Vos JG. Highly ordered surface structure of large-scale porphyrin aggregates assembled from protonated TPP and water. J Mol Struct. 2014;1065:170-8.

30. Sharman WM, Allen CM, Van Lier JE. Photodynamic therapeutics: basic principles and clinical applications. Drug Discov Today. 1999;4(11):507-17.

31. Detty MR, Gibson SL, Wagner SJ. Current clinical and preclinical photosensitizers for use in photodynamic therapy. J Med Chem. 2004;47(16):3897-915.

32. Sharman WM, van Lier JE, Allen CM. Targeted photodynamic therapy via receptor mediated delivery systems. Adv Drug Deliv Rev. 2004;56(1):53-76.

33. Desoize B, Jardillier J-C. Multicellular resistance: a paradigm for clinical resistance? Crit Rev Oncol Hematol. 2000;36(2):193-207.

34. Perche F, Torchilin VP. Cancer cell spheroids as a model to evaluate chemotherapy protocols. Cancer Biol Ther. 2012;13(12):1205-13.

35. Lee P, Meisel D. Adsorption and surface-enhanced Raman of dyes on silver and gold sols. J Phys Chem. 1982;86(17):3391-5.

36. He X, Wu X, Wang K, Shi B, Hai L. Methylene blue-encapsulated phosphonate-terminated silica nanoparticles for simultaneous $\langle i>$ in vivo </i> imaging and photodynamic therapy. Biomaterials. 2009;30(29):5601-9.

37. Spiller W, Kliesch H, Woehrle D, Hackbarth S, Roeder B, Schnurpfeil G. Singlet oxygen quantum yields of different photosensitizers in polar solvents and micellar solutions. J Porphyrins Phthalocyanines. 1998;2(2):145-58.

38. Mosmann T. Rapid colorimetric assay for cellular growth and survival: application to proliferation and cytotoxicity assays. J Immunol Methods. 1983;65(1-2):55-63.

\section{Submit your next manuscript to BioMed Central and take full advantage of:}

- Convenient online submission

- Thorough peer review

- No space constraints or color figure charges

- Immediate publication on acceptance

- Inclusion in PubMed, CAS, Scopus and Google Scholar

- Research which is freely available for redistribution

Submit your manuscript at www.biomedcentral.com/submit
Ciomed Central 